\title{
TAKING YOUTH SUICIDE SERIOUSLY: DISCLOSURE OF INFORMATION BETWEEN SCHOOL, FAMILY AND HEALTH PROFESSIONALS IN NEW ZEALAND
}

\author{
James G Stewart*
}

This paper investigates the law's impact on disclosures of information between family, school and health professional in curbing the tragedy of youth suicide in New Zealand. The application of general privacy and confidentiality law is considered within the context of the recommended best practice espoused by the state lead New Zealand Youth Suicide Prevention Strategy. The paper concludes that the complexity and at times incoherence of current law has failed to define standards upon which disclosure decisions could be based. As such, the legal obligations of privacy and confidentiality have not been adequately married with the need for cohesion between family, school and health professional or indeed, with the best interests of the suicidal adolescent. Instead the article suggests a separate privacy and confidentiality regime that addresses the particular challenges faced by parties dealing with suicidal young people. The suggestions are based on information obtained from a national survey of secondary school principals in New Zealand.

* James Stewart completed an LLB(Hons) at Victoria University in 1999. His masters thesis focused generally on the law's impact on youth suicide management. The full masters paper on the topic, including questionnaire, survey data and analysis can be downloaded from the internet at <http://members.xoom.com/stewartjames>. 


\section{INTRODUCTION}

In 1998, 78 people between the ages of 10 and 19 committed suicide in New Zealand. ${ }^{1} 30$ were female and 48 male. These figures represent a rate of 17.0 male suicides and 11.3 female suicides per 100,000 population, a figure in which Maori are over-represented. ${ }^{2}$ Since 1985 alone, the rates of suicide for young people within that group have increased by 145 per cent. $^{3}$ Among OECD countries, New Zealand and Finland have suffered the highest rates of youth suicide this decade, ${ }^{4}$ and along with Australia, New Zealand has the ominous distinction of being one of the two Western Countries whose youth suicide rate is higher than the total suicide rate. ${ }^{5}$

The questions which this trend poses to all aspects of society are profound. They are questions which demand research into various issues related to suicide behaviour and prevention, at a range of levels and by a range of organisations and individuals. ${ }^{6}$ Yet surprisingly the discipline of law is an area that has, until now, escaped close scrutiny. That fact is peculiar: first because the management of adolescent suicide behaviours has wide ranging legal implications for all parties concerned; and second, since the vast majority of suicidal adolescents in New Zealand do in fact have contact with management facilities. ${ }^{7}$ This

1 Courtesy New Zealand Health Information Service, 10 October 2000 (provisional data). ["Health Statistics"]

2 Maori - 25.3, non-Maori - 11.2; Health Statistics, above $n 1$.

3 Health Statistics, above $\mathrm{n} 1$.

4 P M Ellis and S L D Collings (eds) Mental Health In New Zealand From A Public Heath Perspective (Public Health Report No 3, Ministry of Heath, Wellington, 1997) 427. ["Public Health"]

5 C Pritchard "Youth Suicide in Australia and New Zealand Compared with Countries of the Western World 1973 - 1987" (1992) 26 Aust NZ Jnl Psyc 609 - 617.

6 In Our Hands: The New Zealand Youth Suicide Prevention Strategy (Ministries of Health, Youth Affairs and Maori Development, Wellington, 1998) 36. ["Prevention Strategy"]

7 Almost 80 per cent of serious suicide attemptees have had extensive and recent contact for psychiatric problems with a range of services prior to the suicide attempt, 58 per cent within the month prior to the attempt. See Canterbury Youth Suicide Project Psychiatric Illness in a New Zealand Sample of Young People making Serious Suicide Attempts (Bulletin No 11, August 1997) <http://www.chmeds.ac.nz/research/suicide/bull11.htm>. 
article examines one aspect of the law's impact on that process. It addresses the regulation of the flow of information between school, family and mental health professional in the management of youth suicide in New Zealand.

The issue is pertinent since the effectiveness of steps taken to prevent suicidal behaviours, by any of those parties, depends on an ability to make informed decisions in the best interests of each suicidal adolescent. That ability invariably demands cohesion. As Schaefer concluded: 8

Both parent and professional care of the child have direct benefits to child health and development,

but ... parents and professionals also have indirect effects upon the child through their interaction with one another.

That reality was brought home to the Mason Inquiry into Mental Health Services by one submission that explained how: ${ }^{9}$

The week before our daughter took her life, I phoned the psychiatrist to say that she had put up a

"noose." The psychiatrist asked if I had my daughter's permission to call.

As that unfortunate family discovered, an ability to facilitate necessary cohesion is subject to complex privacy and confidentiality law. Obligations of confidentiality stem from a special relationship based on a degree of reliance or trust. ${ }^{10}$ Both reliance and trust are important features of relationships that deal with suicidal adolescents. Without a significant degree of trust, many potentially suicidal teenagers will be deterred from seeking assistance by the stigma attached to treatment and the humiliation involved in loss of privacy. A relationship of trust is also key to addressing an individual's conscious and unconscious inhibitions to psychotherapeutic relationships. ${ }^{11}$

8 E S Schaefer "Professional support for family care of children" in H M Wallace and others (eds) Maternal and Child Health Practices: Problems, Resources and Methods of Delivery (2 ed, Wiley, New York, 1982) 3.

9 Mason Report Inquiry Under s 47 of the Health and Disability Services Act in Respect of Certain Mental Health Services (Ministry of Health, Wellington, 1996) 51.

10 John Dawson "The Discretion to Warn Potential Victims: Damned if you do, damned if you don't?" (1994) 1 Mental Health and the Law 9, 10.

11 Joan Neisser "Disclosing Adolescent Suicidal Impulses to Parents: Protecting the Child or the Confidence?" (1993) 26 Ind L R 433, 444. 
A breach of confidentiality may also have undesirable effects for the professional. The sense of betrayal felt by the young person may destroy any chance of that relationship being rekindled for treatment purposes at a later time. In the more immediate future, a breach may have the unintended consequence of exacerbating suicidal tendencies, ${ }^{12}$ or have implications for other suicidal young people, especially in a closed community such as a school.

While privacy obligations will be critical in a confidential relationship, they may derive independently of any such relationship. ${ }^{13}$ Given the sensitive nature of the information involved in suicide management, privacy implications will often be involved outside the confines of a confidential therapeutic relationship.

The difficulty for law in facilitating appropriate suicide management is to marry privacy and confidentiality concerns with the need for cohesion between family, school and health professional. Yet as will be seen, this is not a difficulty the law has well addressed.

\section{SUICIDE MANAGEMENT: THE STATE OF THE ART}

In March 1998 The Ministry of Youth Affairs published a strategy entitled In Our Hands: New Zealand Youth Suicide Strategy ("The Strategy"). The mission of the report was:

...to help government, communities, and families/whanau and individuals act together to reduce youth suicide and suicidal behaviours.

The principles of the strategy are based on a report undertaken by Dr Annette Beautrais entitled In Our Hands: A Review of the Evidence. ${ }^{14}$ They provide a framework for understanding suicide prevention and signal the steps that must be taken by a range of governmental agencies, community services, hapu and iwi to reduce youth suicide. ${ }^{15}$

A further State initiated response to the crisis acknowledges the role of the education system in suicide management. The Prevention, Recognition \& Management of Young People at

12 J Langton and D Torpy "Confidentiality and a 'Future' Sadistic Sex Offender" (1988) 28 Med Sci Law $195,198$.

13 Dawson, above n 10, 10.

14 Annette Beautrais In Our Hands: Review of the Evidence (Ministry of Health, Wellington, 1998) ["Review of the Evidence"]

15 Prevention Strategy, above n 6, 6. 
Risk of Suicide: Development of Guidelines For Schools ${ }^{16}$ ("Guidelines for Schools") was commissioned by the Ministry of Education in collaboration with the National Advisory Committee on Health and Disability. Its purpose is to summarise the research literature and identify best practice to assist in the development of guidelines for schools, taking into account the role of family and professional agencies.

The literature makes it clear that the management of suicidal behaviours usually involves several overlapping stages: recognition, prevention, intervention and postvention. ${ }^{17}$ Determining the appropriate level of involvement hinges on the recognition of the young person's risk of life threatening behaviour, a skill which despite guidelines ${ }^{18}$ can only be adequately achieved by subjective, intuitive expertise. ${ }^{19}$ The recognition process is premised by the notion that the intensity of suicidal behaviours ebbs and flows across a continuum, ranging from suicidal ideation at one extreme to completion at the other. ${ }^{20}$

The process of intervention is concerned solely with the immediate actions required to save a person's life in the acute phase of that cycle. ${ }^{21}$ Suicide "prevention", on the other hand, involves a system that responds to suicidal behaviour in chronic stages, where risk is less imminent. The term "prevention", used here in a refined sense as a specific aspect of suicide management, involves psychological counselling and treatment directed at helping the young person overcome his or her difficulties. Within that context, postvention refers to a variety of

16 A L Beautrais, C A Coggan, D M Fergusson and L Rivers The Prevention, Recognition and Management of Young People at Risk of Suicide: Development of Guidelines for Schools (Ministries of Education and National Advisory Committee of Health and Disability, Wellington, 1997) ["Guidelines for Schools"]

17 Margaret Pabst Battin Ethical Issues in Suicide (1995, Prentice-Hall, New Jersey) 12.

18 Current risk factors cannot reliably predict suicidal behaviour and are not predictive of suicidal events. They thus yield many false positives: individuals who satisfy assessment criteria but fail to go on and complete suicide. See Phillip Hazell and Ray King "Arguments for and Against Teaching Suicide Prevention in Schools" (1996) 30 Aust and NZ Jnl of Psyc 636; A D Pokorny "Prediction of Suicide in Psychiatric Patients: A Report of A Prospective Study" (1983) 40 Archives of General Psychiatry 249.

19 CA Coggan Community Based strategies to Address Youth Suicide: Development, Implementation and Formative Evaluation. (PhD Thesis, University of Auckland, 1996) in Guidelines for Schools, above n 16, 24.

20 Cynthia R Pfeffer The Suicidal Child (The Guilford Press, London, 1986) 19.

21 Guidelines for Schools, above n 16, 33. 
counselling and therapy services offered to the person who has attempted suicide but survived, or to the survivors of persons who have actually killed themselves. ${ }^{22}$

These various aspects of suicide management involve family, health professional and school differently. The remainder of this article examines the laws of privacy and confidentiality relevant to each of these groups in turn. The article will show that appropriate management of suicidal tendencies may be impaired by the myriad of legal provisions that dictate the levels to which the relevant parties can interact.

\section{DISCLOSURES BY HEALTH PROFESSIONALS}

\section{A The Privacy Act 1993 and The Health Information Privacy Code 1994}

Currently, the limits of a health professional's duty of privacy are largely governed by legislation, in the form of the Health Information Privacy Code 1994 ("HIP Code"). The Code, which took effect on 30 July 1994, was issued by the Privacy Commissioner under section 46 of the Privacy Act 1993.

The purpose of the HIP Code is to provide greater protection to patients in their dealings with health professionals by applying specific rules for the information privacy principles in the Privacy Act. ${ }^{23}$ It acknowledges that agencies will have to balance retaining a patient's trust and fulfilling their functions as health professionals. According to the Commissioner, that "might sometimes include acting in what they believed to be a patient's best interests even if the patient disagree[s]." 24

\section{Health information}

The application of the HIP Code is restricted to health information. The term is defined by rule 4(1) to include five classes of information which address the person's health, disabilities, or treatment. ${ }^{25}$ The HIP Code inarguably applies to the status of a young person's suicidal tendencies.

22 Battin, above $\mathrm{n} 17,16$.

23 Marie E Burgess (ed) Complying with Codes in The Health Sector (Rakanui Publications, Wellington, 1997) 10 .

24 Privacy Commissioner Mental Health Professionals and Patient Information: Guidelines (Wellington, 1997$) 15$. ["Patient Information"]

25 Burgess, above n 23, 15. 


\section{Consent and disclosure}

As a general rule, health information cannot be disclosed without express or implied consent. ${ }^{26}$ The list of exceptions to that position in rule 11(2) provide that non consensual disclosures may only proceed where "the health agency believes on reasonable grounds that it is either not desirable or not practicable to obtain authorisation" from the individual concerned. ${ }^{27}$

In some instances the risk of seeking consent from a suicidal teenager may have the effect of heightening the risk of suicide. In those circumstances, seeking consent is clearly not "desirable." ${ }^{28}$ But in the absence of that risk, attempts to obtain consent should always be made. Consequently, in cases of prevention, suicidal individuals have as much of a right to privacy in treatment as anyone.

In the event that the young person explicitly wishes to preclude the involvement of a third party, consent will need to be "not practicable" in order for disclosure to go ahead. It seems clumsy to use the phrase "not practicable" to describe a situation involving an individual's explicit refusal to disclose, yet subsequent rules are only made cogent by that interpretation. By that somewhat ambiguous process, consent may be dispensed with all together.

In addition to the requirement that consent be "not desirable or not practicable," disclosure must also be justified on the basis of reasonable belief in one of the many other circumstances included in rule 11 including: that the disclosure is to the patient or patient's representative, ${ }^{29}$ that the disclosure is consistent with the purposes for which the information was obtained, ${ }^{30}$ or that the information is publicly available. ${ }^{31}$ The most pertinent basis for disclosure of adolescent suicidal tendencies is in rule $11(2)(\mathrm{d})$ : the "serious and imminent danger of harm".

26 Health Information Privacy Rules 1994, r 11(1).

27 Health Information Privacy Rules 1994, r 11(2).

28 Dawson, above $\mathrm{n} 10,11$.

29 Health Information Privacy Code 1994, r11(1)(a).

30 Health Information Privacy Code 1994, r11(1)(c).

31 Health Information Privacy Code 1994, r11(1)(d). 


\section{Serious and imminent danger}

The rule in 11(2)(d) of the HIP Code provides a discretion to disclose information if it is necessary to prevent or lessen a serious and imminent threat to public health or public safety, or the life or health of any individual, including the patient. The rule is based on the common law principle that: ${ }^{32}$

...although the basis of the law's protection of confidence is that there is a public interest that confidences should be preserved and protected by the law, nevertheless that public interest may be outweighed by some other countervailing public interest which favours disclosure... It is this binding principle which may require a court to carry out a balancing operation, weighing the public interest in maintaining the confidence against a countervailing public interest favouring disclosure.

The key aspects are thus: ${ }^{33}$

- The risk of harm is serious.

- The risk of harm is imminent.

- The nature of the harm may be either to the young person themselves or to the health or safety of the public.

- The information must be given to someone who can act to prevent or lessen the harm.

- Only the information necessary to prevent the suicide should be given which may not involve disclosing all information.

The requirements of seriousness and imminence can conveniently correspond to the high risk assessment criteria as set out in the Guidelines to Schools. ${ }^{34}$ But the danger is that the unchecked professional could justify all disclosures based on their intuitive and subjective assessment. Furthermore, it is difficult to determine exactly who will qualify as a party able to prevent or lessen the harm involved in youth suicide. It is also difficult to delineate between information that is necessary to prevent the suicide and information that is irrelevant to that process. As subsequent sections will show, the consequences of these imprecisions are likely to be significant.

32 AG v Guardian Newspapers Ltd (No 2) [1988] 3 All ER 545, 545 and 559 (HL) per Lord Goff.

33 Patient Information, above n 24, 19.

34 Guidelines for Schools, above n 16, 24. 


\section{Remedies, duties and discretions}

Parties disaffected by breaches of the HIP Code in suicide management may seek redress through provisions of the Privacy Act. Section 53 of the Act deems failure to comply with the HIP Code a breach of an information privacy principle under part VII of the Act. Complaints are initially directed to the Privacy Commissioner who has a discretion to determine whether investigation is merited. ${ }^{35}$ Should attempts at reconciliation fail, civil proceedings can be brought before the Complaints Review Tribunal. ${ }^{36}$ If that Tribunal considers there to have been an "interference with the privacy of an individual"37 it has the discretion to award declarations of interference, restraining orders, damages, costs and other remedial orders as it thinks fit. 38

A key distinction in questions of interference is the difference between a duty and a discretion. The beneficiary of a duty has a right to demand the information and production can be compelled by a Court but in the case of a discretion, the potential recipient is entitled to request the information but has no right to it. ${ }^{39}$ The disclosure provisions in rule 11 of the HIP Code provide only discretions. A health professional may thus decline to disclose suicide information even though the request satisfies the requirements of the Code. The Health Act 1956 on the other hand creates a duty to disclose in specific situations.

\section{B The Health Act 1956}

The HIP Code and Privacy Act are not the only legislative provisions relevant to questions of disclosure for Health Professionals. Confusingly, section 22F of the Health Act 1956 also addresses those same issues.

Unlike the specific rules established by the HIP Code, section 22F of the Health Act 1956 serves a number of different purposes. Apart from giving patients access to their own information, it also regulates requests for access by the representative of a patient, and

\footnotetext{
35 Privacy Act 1993, s 71.

36 Privacy Act 1993, s 82.

37 Privacy Act 1993, s 66.

38 Privacy Act 1993, ss 84, 85 and 88.

39 Dawson, above n 10, 9.
} 
requests for access by third parties. ${ }^{40}$ In each case the professional has a duty to disclose the information requested unless he or she can satisfy one of the criteria in section $22 \mathrm{~F}(2){ }^{41}$

Section $22 \mathrm{~F}(2)$ specifies three grounds for refusing disclosure: ${ }^{42}$

(a) that the person holding the information is able to show that they had a lawful excuse for doing so,

(b) where the information is requested by someone other than the individual or their representative, that the information holder has reasonable grounds for believing the individual does not wish the information to be disclosed, or

(c) refusal is authorised by a code of practice issued under section 46 of the Privacy Act 1993.

There is some conceptual difficulty in determining the relationship between these grounds for refusing to disclose, and the discretion to disclose under the HIP Code. The difficulty arises because section $22 \mathrm{~F}(3)$ explicitly states that a breach of the principles of the Privacy Act is not a lawful excuse for refusing disclosure under section $22 \mathrm{~F}(2)(\mathrm{a})$. The peculiarity is that a breach of the Privacy Act principles cannot found a refusal to disclose under section $22 \mathrm{~F}(2)(\mathrm{a})$; but a Code issued pursuant to the Privacy Act can, under section $22 \mathrm{~F}(2)(\mathrm{c})$. The somewhat trite solution is that a refusal to disclose on the basis of the Privacy Principles is not a lawful excuse, but a refusal consistent with the Code is. ${ }^{43}$ Nevertheless, parties involved in the complex process of suicide management can be excused for not understanding their obligations under current legislation.

\section{A Common Law Duty to Warn}

Neither the Health nor Privacy Acts purport to govern all aspects of patient privacy. Both expressly acknowledge the professional's potential liability for breach of privacy outside the confines of the Acts. ${ }^{44}$ Since a litigant would not have the statutory bar erected by section 394

40 Nicola S Peart "Access to, and Disclosure of, Health Information: Are the Rules in Need of a 'New Treatment'?" (1996) 2 Human Rights Law and Practice 95, 100.

41 Peart, above n 40, 100.

42 Health Act 1956, s 22F(2).

43 Peart, above n 40, 97.

44 Privacy Act 1993, s 115; Health Act 1956, s 5. 
Accident Insurance Act 1998 to contend with, ${ }^{45}$ a breach of any civil duty which leads to physical harm could give rise to civil proceedings against the professional.

Common law has arguably gone further than the HIP Code by recognising that in rare circumstances practitioners are obliged to divulge certain confidential information. ${ }^{46}$ In Furniss v Fitchett Barrowclough CJ announced that disclosure is "require[d]" when a doctor: ${ }^{47}$

...discovers that his patient entertains delusions in respect of another, and in his disordered state of mind is liable at any moment to cause death or grievous bodily harm to that other. Can it be doubted for one moment that the public interest requires him to report that finding to someone?

More recently in Duncan v Medical Practitioners Disciplinary Council Jeffries J stated: ${ }^{48}$

There must be occasions, they are fortunately rare, when a doctor receives information involving a patient that another's life is immediately endangered and urgent action is required. The doctor must then exercise his professional judgement based upon the circumstances, and if he fairly and reasonably believes such a danger exists he must act unhesitatingly to prevent injury or loss of life even if there is to be a breach of confidentiality.

The duty to warn was expressed in stronger terms in the much publicised Californian case of Tarasoff $v$ Regents of the University of California, where the Court declared: ${ }^{49}$

[O]nce a therapist does in fact determine, or under applicable professional standards reasonably should have determined, that a patient poses a serious danger of violence to others, he bears a duty to exercise reasonable care to protect the foreseeable victim of that violence... The protective privilege ends where the public peril begins.

In that case, a psychiatrist employed by the student medical centre at the University of California told the staff of his patient's violent intentions towards a female student. Although

45 Section 120 of the Accident Insurance Act 1998 states that an insurer is not liable to provide any statutory entitlement for a personal injury that an insured wilfully inflicts on himself or herself. Thus, even though suicidal behaviours might satisfy the definitions of accident and personal injury, such injuries are not covered by the scheme and thereby avoid the bar to civil action.

46 Dawson, above $\mathrm{n} 10,14$

47 Furniss v Fitchett [1958] NZLR 396, 405 (SC).

48 Duncan v Medical Practitioners Disciplinary Council [1986] 1 NZLR 513, 521 (HC) per Jeffries J.

49 Tarasoff v Regents of the University of California (1976) 551 P 2d 334, 347 (SC Cal) En Banc. 
the police were warned the student was not. Subsequently the woman was murdered and the medical centre found liable for its failure to breach the patient's confidentiality and warn the woman of the threat to her life.

Although the decision in Tarasoff has been widely criticised ${ }^{50}$ and the value of both Furniss $v$ Fitchet ${ }^{51}$ and Duncan v Medical Practitioners Disciplinary Council ${ }^{52}$ as precedents is largely untested, all three have potential implications for health professionals dealing with suicidal adolescents. Their relevance depends on whether danger to oneself is sufficient to trigger the duty.

In Bellah $v$ Greenson, ${ }^{53}$ a Californian Court found that Tarasoff did not require a therapist to warn parents of their child's suicidal inclinations. According to the Court in Bellah, Tarasoff did not require therapists to warn others of the likelihood of any and all harm. The Court was concerned that the therapeutic relationship would be compromised if therapists revealed that their patients manifested suicidal tendencies. Unlike the third party situation, the need for confidentiality was not outweighed by the risk of suicide because the imposition of such a duty could well "inhibit psychiatric treatment." 54

50 See A Stone Law, Psychiatry and Morality: Essays and Analysis (American Psychiatric Press, Washington DC, 1984) Ch 7.

51 Furniss $v$ Fitchett [1958] NZLR 396 (SC).

52 Duncan v Medical Practitioners Disciplinary Council [1986] 1 NZLR 513 (HC).

53 Bellahv Greenson (1977) 141 Cal Rptr 92 (CA Cal).

54 Neisser, above n 11, 445. 
Yet that interpretation of Tarasoff, creates the absurdity that family ${ }^{55}$ or community ${ }^{56}$ might be contacted for their own sake but not for the interests of the suicidal young person. It is also difficult to see how the distinction between a discretion and a duty has any greater effect of "inhibit[ing] psychiatric treatment." One would assume that such a duty would only be triggered in acute cases as assessed by professional and independent supervisor. Unfortunately, resolution of that debate remains academic. In practice, the existence and extent of a professional's obligation at common law cannot be clearly determined.

\section{Other Sources of Law}

Because suicide management encompasses such a wide range of relationships and circumstances, parties involved with suicidal young people also have potential legal obligations arising from other sources of law. ${ }^{57}$

\section{Codes of ethics}

Although ethical codes also set out a range of obligations, by themselves they only provide means for independent disciplinary hearings to be conducted by the relevant professional association. Ethical codes will be significant however, in recommending to the courts a standard to be followed when exercising a discretion.

55 Immediate family can be up to five times more likely to attempt or complete suicide following completed suicide of a family member. D A Brent and others "Suicidal Behaviour Runs in Families" in Kosky and others (eds) Suicide Prevention (Pelnum Press, New York, 1998) 53. They also face complex emotional, personal and social vulnerability characterised by divorce, marital problems, problems with children, psychological disorders and institutionalisation. See Monique Séguin, Alain Lesage, Margaret Kiely "Parental Bereavement After Suicide and Accident: A Comparative Study" (1995) 25 Suicide and Life Threatening Behaviour 489, 490.

56 A suicide cluster is the general term for the causal link between two (or more) suicidal behaviours. In general, research shows that clustering accounts for a maximum of 5 per cent of teenaged suicides in the United States. See Philip Hazell "Adolescent Suicide Clusters: Evidence, Mechanisms and Prevention" (1993) 27 Aust and NZ Jnl Of Psyc 653, 661 and P W O'Carroll, J A Mercy, J A Stewart "CDC Recommendations For A Community For The Prevention And Containment Of Suicide Clusters" (1988) 37 Morbidity and Mortality Weekly Report 1 - 12.

57 Wayne Herdy "Must the Doctor Tell?" (1996) 3 Jnl of Law and Med 270, 272. 


\section{Contract}

If a contract exists between the parties the courts readily construe an implied term of confidentiality. ${ }^{58}$ The extent of the obligation of confidentiality will turn on the nature of the relationship and expectations of the parties to the contract.

A young person is capable of enforcing an implied term of confidentiality against a professional. ${ }^{59}$ For the most part, the treatment of suicidal young people will occur where there is no direct contractual relationship between the health care provider and the young person or his or her family. This absence of contractual consideration would extend to most publicly funded mental health institutions, including Crisis Assessment Teams, making the contractual basis of confidentiality unlikely. Even if there were adequate consideration to support a contract, a young person would generally lack privity to an agreement formed between parents and professional. In that instance a contractual analysis would seem to favour the parents' interests over and above those of the child. Yet although obligations arising out of contract might be rare, they are a concern that should not be ignored.

\section{Equity}

At equity, the fundamental basis of a professional's duty not to disclose confidential information is the concept of the fiduciary obligation. In Duncan $v$ Medical Practitioners Disciplinary Council Jeffries J said: ${ }^{60}$

The platform support of a description of medical confidence is to identify the doctor/patient relationship as a fiduciary one.

It is now settled law that a professional who breaches his or her fiduciary duty of confidence is liable to pay compensatory damages. ${ }^{61}$ However, in terms of a professional's liability, clear distinctions between sources of confidence may now be less important. As the Court of Appeal noted in Aquaculture Corp $v$ NZ Green Mussel Co: ${ }^{62}$

58 See Cosco (New Zealand) Ltd v Port of Napier Ltd (31 March 1999) unreported, High Court, Napier Registry CP 7/99.

59 Minors' Contracts Act 1968, s 6.

60 Duncan v Medical Practitioners Disciplinary Council [1986] 1 NZLR 513, 520 (HC) per Jefferies J.

61 Day v Mead [1987] 2 NZLR 443 (CA).

62 Aquaculture Corp v NZ Green Mussel Co [1990] 3 NZLR 299, 301 (CA). 
The practicality of the matter is that in the circumstances of the dealings between the parties the law imposes a duty of confidence. For its breach a full range of remedies should be available as appropriate, no matter whether they originated in common law, equity or statute.

Thus common law, ethical, contractual and equitable obligations will all be highly relevant in determining whether the exercise of a discretion under the HIP Code is justified. So while the HIP Code presents the outer limits of legitimate breaches of privacy, it does not help establish when and how a suicidal young person's tendencies should be disclosed. The question remains: how then does law currently affect disclosures of information between family, school and mental health professional?

In order to answer that question fully, the remainder of this article draws on information obtained from a national survey of secondary schools. ${ }^{63}$ The anonymous questionnaire to principals asked 27 broad questions on the demographics of the school, suicidal behaviours, reporting of suicide risk, training, postvention plans and referrals. The results of that survey have implications for each specific party involved in suicide management.

\section{E Health Professionals and Disclosures to Family}

\section{The family's role in prevention and treatment}

Family generally play a critical role in suicide treatment and prevention, particularly when the individual is a young person. According to the Guidelines for Schools: ${ }^{64}$

Where the possibility of suicide is a particular concern, it is important to speak with the family.... A decision to contact their family should also take into account the likely impact on the person's current and future relationship.

In many instances parents will have a legitimate role in management through the exercise of guardianship powers, ${ }^{65}$ but evidence also indicates the importance of family involvement from a psychological perspective. ${ }^{66}$ Such importance must be weighed against the concern that family abuse is a major precipitating cause of suicidal behaviours in adolescents: a

63 Of the 447 secondary schools in the country, 230 made detailed replies; a response rate of 51 per cent.

64 Guidelines for Schools, above n 16, 32.

65 Parents have rights and responsibilities for the "upbringing" and "development" of their children: Guardianship Act 1968, s 3; United Nations Convention on the Rights of the Child, art 18.1.

66 Neisser, above n 11, 434. 
concern apparently well founded in New Zealand. ${ }^{67}$ Among the schools surveyed here 97 cases were not disclosed to parents based on the possibility of abuse, indicating that schools are concerned about abuse in nearly one of every five instances. Given these competing agendas, how do the laws surrounding privacy and confidentiality affect a parent's ability to assist in their child's suicide treatment?

\section{Family as representatives and the relevance of abuse}

As has been seen, both rule 11 of the HIP Code and section 22F Health Act 1956 provide representatives with rights to patient information. Section $22 \mathrm{~B}(\mathrm{~b})$ of the Health Act 1956 defines a "representative" as the parent or guardian of an individual under the age of 16 years. Subsection (c) also includes a person appearing to be lawfully acting on the individual's behalf or in that individual's interests when the individual is unable to give his or her consent or authority. Both sections trigger the duty to disclose under section $22 \mathrm{~F}$ of the Health Act unless an agency is able to satisfy one of the grounds in section $22 \mathrm{~F}(2)$. But add to those provisions, the confusion in rule 11(4) of the HIP Code.

Rule 11(4) was an eleventh hour amendment to the temporary HIP Code in response to the concern that parents suspected of abusing their children could demand access to their child's medical records. ${ }^{68}$ Rule 11(4) of the HIP Code now directs that where a representative requests disclosure of information pursuant to section $22 \mathrm{~F}(1)$ of the Health Act 1956, the health agency must treat the request under rule 6 and may refuse to disclose information to the representative if:

Disclosure would be contrary to the young person's best interests, or

The agency has reasonable grounds for believing that the individual would not consent.

Rule 6 addresses access to personal health information. The only restriction on access is through Parts IV and V of the Privacy Act. In combination with rule 11(4) a representative must disclose the information unless one of the criteria in rule 11(4)(b) can be made out. Unfortunately, rule 11(4)(b) adopts a very broad test for non-disclosure: "reasonable grounds for believing", and "contrary to the young person's best interests". The breadth of those tests

67 One study links one third of all suicide attempts with sexual abuse. See S E Romans, J L Martin, J C Anderson, G P Herbison and P E Mullen "Child Sexual Abuse and Deliberate Self Harm" (1995) 152 American Jnl of Psyc 1336 - 1342.

68 Peart, above $\mathrm{n} 40,100$. 
undermines the purpose of the duty in a number of ways; particularly in the context of suicide management.

A duty to disclose to parents is only triggered when a request for information is received by the agencies. There can be no duty under the Health Act or HIP Code to disclose a young person's suicidal tendencies to his or her parents when parents themselves have no cause for suspicion or alarm. Even then the section allows agencies to rely on a wide range of reasons to justify refusal. In addition, rule 11(4) makes no reference to the criteria in section 14 of the Children, Young Persons and Their Families Act 1989, which specifically govern when a parent's right to involvement may be dispensed with.

Furthermore, since families are often required to be involved in the ongoing treatment of suicidal young people, they will invariably come within the scope of providers of "health and disability services" for the purposes of section 22F of the Health Act. Section 22B of the Health Act adopts the definitions of health and disability services as enacted in section 2 of the Health and Disability Services Act 1993. The definitions state: ${ }^{9}$

"Health services" includes goods, services, and facilities provided to people for health purposes or provided for related or incidental purposes.

"Disability services" includes goods, services, and facilities--

(a) Provided to people with disabilities for their care or support or to promote their independence; or

(b) Provided for purposes related or incidental to the care or support of people with disabilities or to the promotion of the independence of such people

Both definitions are sufficiently broad to include the extensive treatment and support provided by family. Thus even if a young person is competent ${ }^{70}$ and able to exclude family from decisions involving treatment, the family will often have a right to certain private information. ${ }^{71}$ Not only is that conclusion painfully obscure, it also undermines the young

69 Health and Disability Services Act 1993, s 2.

70 Either by having reached the age of 16 years: Guardianship Act 1968, s 25; or having demonstrated a sufficient understanding and intelligence to be capable of making up his or her own mind. See Gillick $v$ West Norfolk and Wisbech Area Health Authority [1986] AC 112 (HL).

71 Subject of course to the best interests of the young person when they are under the age of 16 years: Health Information Privacy Code 1994, r 11(4). 
person's ability to make autonomous decisions ${ }^{72}$ and ignores the concerns underlying rule 11(4) of the HIP Code.

The use of that Code to amend section $22 \mathrm{~F}$ of the Health Act is, at best, enormously confusing. At worst, rule 11(4) is an illegitimate use of section 46 Privacy Act because it has the unconstitutional effect of repealing legislation. In either case, the shear volume and complexity of the law leave serious doubts whether disclosure of suicidal tendencies to family during treatment could be consistent or principled.

\section{Disclosures to parents in emergency intervention}

During the acute phase of suicidal behaviours, rule 11(2)(d) HIP Code provides clear scope for disclosing a young person's suicidal tendencies to his or her parents. The provision permits a health professional to warn an appropriate third party if it is necessary to prevent or lessen a serious threat of imminent harm. Yet because section 11(4) only applies to duties to disclose under section $22 \mathrm{~F}$ Health Act, there is no requirement that likelihood of abuse should be considered in emergencies. Furthermore, although the use of rule 11(2)(d) will provide justification for a health agency's disclosure to parents, it does not indicate whether the agency is obliged to do so.

As previous sections show, common law does not help establish when such a duty is owed. That indeterminancy leaves health professionals guessing between privacy, confidentiality, ethics, duties, discretions and the best interests of suicidal young people.

\section{DISCLOSURES INVOLVING SCHOOLS}

\section{A Disclosure by Schools to Mental Health Professionals}

According to the Guidelines for Schools, management of a young person at high risk of suicide requires the: ${ }^{73}$

...Counsellor to make a referral to an appropriate health professional (GP, SES, mental health services) for further assessment and primary management.

72 Parental rights yield to the child's rights to decide when that child reaches a sufficient understanding and intelligence to be capable of making up his or her own mind. See Gillick $v$ West Norfolk and Wisbech Area Health Authority [1986] AC 112 (HL).

73 Guidelines for Schools, above n 16, 31. 
In 1998, schools responding to the survey made 638 referrals to mental health agencies. As a form of intervention, those referrals intersect with requirements for committal under the Mental Heath (Compulsory Assessment and Treatment) Act 1992 ("MH(CAT) Act"). ${ }^{74}$

\section{Suicidal intervention under mental health legislation}

Under the previous Mental Health Act 1969, the definition of mental disorder which justified committal for primary management was supplemented by section 126A of the Health Act 1956. Section 126A provided for committal of individuals who had survived a suicide attempt. Committal of any survivor of suicidal behaviour was justified independently of psychiatric opinion of their mental state. A District Court Judge could incarcerate an individual for up to three months ${ }^{75}$ where satisfied that the individual was in need of care, treatment or remained suicidal. ${ }^{76}$ The Court had power to define the nature and conditions of the order as it saw fit. $^{77}$

The enactment of the MH(CAT) Act brought significant changes to the assessment and treatment of mentally disordered individuals. It "redefined" the circumstances and conditions under which compulsory psychiatric assessment and treatment could occur by adopting a more restrictive definition of the term "mental disorder" and by instigating a rebuttable presumption that all patients are to be treated in the community. ${ }^{78}$ The change in philosophy coincided with the repeal of section 126A of the Health Act 1956. Thus to be subject to a compulsory assessment and treatment order, it is no longer sufficient to be suicidal unless the grounds for mental disorder in section 2 of the MH(CAT) Act can be met. Theoretically then, the suicidal individual has less recognition under current law than under the previous Health Act, a result that seems counterintuitive given the sharp increase in suicide across the entire

74 Although significantly less common, committal or its equivalent can also be achieved through the Alcoholism and Drug Addiction Act 1966; Protection of Personal and Property Rights Act 1988 and Children Young Persons and their Families Act 1989.

75 Health Act 1956, s 126A(1)(a) (repealed).

76 Health Act 1956, s 126A(2) (repealed).

77 Health Act 1956, s 126A(3) (repealed).

78 All patients are subject to a community treatment order unless a Court considers that they cannot be treated adequately as an outpatient. Mental Health (Compulsory Treatment and Assessment) Act 1992, s $28(2)$. 
population over the same period. ${ }^{79}$ In fact recent statistics indicate that the process has been detrimental to suicide management in the wider community. ${ }^{80}$

The effects of these trends on a school's decision to refer a young person to the mental health system are speculative. There is the danger however that schools are disillusioned by mental health services, particularly child psychiatric care, ${ }^{81}$ and choose alternative systems of emergency intervention that they perceive to be more successful. That possibility finds some support in the fact that, from the schools responding to survey, in 199856 referrals were made to parties other than parents or mental health agencies. Perhaps more alarming is the finding that 15 per cent of school principals had not established criteria that set out when disclosures would be made and to whom. All trends re-emphasise the need for law to ensure that suicide information is properly disclosed to those "who can [appropriately] act to prevent or lessen the harm."

\section{Disclosures to mental health professionals in intervention}

The types of disclosures made to mental health professionals in emergencies, are precisely those anticipated by rule 11(2)(d) of the HIP Code. So long as a serious and imminent risk of suicide can be made out, there could be no argument that mental health professionals are appropriate recipients.

But again the rule in 11(2)(d) merely gives health agencies a discretion to refer young people to a variety of further agencies. As the previous section indicates, lack of confidence in mental health services, ${ }^{82}$ and the inherent subjectivity of suicidality assessment might make a discretion inappropriate. Regrettably there is nothing in the rule to ensure that referrals are made to a party most appropriate for the young person even though the Guidelines for Schools

79 Suicide Trends in New Zealand 1974 - 94 (Ministry of Health, Wellington, 1997) 7.

80 Over the last four years 84 per cent of mental health patients who committed suicide died under the care of community mental health services. While the number of inpatient suicides has remained about the same, the number of outpatient suicides has increased in each of the last four years, and overall has doubled since 1994. Alliance Party "273 Mental Health Patients Take Own Lives" (27 July 1999) Press Release, 1.

81 The Mason Report was particularly critical of child psychiatric services; Mason Report, above n 9, 131 136.

82 The argument also applies to provision of services by the Department of Child Youth and Family Services. 
recommend that this happens. ${ }^{83}$ For example, it may be that the specific requirements of Pacific Island and Maori teenagers, a group currently over represented in suicide statistics, are better dealt with by a different agency than other racial groups.

At common law, where a duty to warn is established the question is not whether to disclose but to whom. ${ }^{84}$ A common law duty might suffice to ensure the best interests of the suicidal patient are met except for the uncertainty of its application.

\section{B Disclosures by Schools to Parents}

The Guidelines for Schools states that: ${ }^{85}$

Once a young person has been identified as being at risk of suicide (no matter how small that risk) staff should refer the young person to the counsellor or a similar designated person for assessment... The counsellor will assess the risk of self harm and inform the principal as appropriate... The principal will inform any other staff and the young person's parent/guardian as appropriate.

Because the counsellor plays a key role in both accumulating information from staff members and disclosing it to principals, families and beyond, the legal obligations affecting the role are enormously important.

\section{School counsellors as health agencies under the code}

The application of the Health Information Privacy Act 1994 is restricted to agencies defined in rule 4(2) of the HIP Code. Rule 4(2)(f) includes "a person who is approved as a counsellor for the purposes of the Accident Rehabilitation and Compensation Insurance Act 1992." In order for a counsellor to satisfy that criteria, he or she was required to be approved by a committee under regulation 4 of the Accident Rehabilitation and Compensation Insurance (Counselling Costs) Regulations $1992 .{ }^{86}$ Although that regulation is now repealed, it has been substantially replicated in the new scheme. ${ }^{87}$

83 Guidelines for Schools, above n 16, 37.

84 Duncan v Medical Practitioners Disciplinary Council [1986] 1 NZLR 513 (HC).

85 Guidelines for Schools, above n 16, 24.

86 Accident Rehabilitation And Compensation Insurance (Counselling Costs) Regulations 1992, S R 1992/268 (revoked).

87 Although there has been no amendment to the Code to account for this change, the oversight is unlikely to have any practical effect. 
The Accident Insurance ("Counsellor") Regulations 1999 establish a host of criteria that counsellors are required to satisfy in order to be approved for payment. ${ }^{88}$ Many of the criteria are those that school counsellors lack: a supervising scheme, ${ }^{89}$ membership to an approved ethical association, ${ }^{90}$ minimum educational requirements and relevant experience. ${ }^{91}$

Thus because many school counsellors will not be registered under the Accident Insurance Act 1998, they will not satisfy rule 4(2)(f) of the Code.

Alternatively, a school counsellor may qualify under rule $4(2)(b)$ as:

A division or administrative unit (including an individual) which provides health and disability

services to employees of the agency or some other limited class.

Ultimately, the very wide definitions of health and disability services are likely to include any school staff member who acts specifically in the capacity of a school counsellor. However, that interpretation is far from clear from a cursory reading of the HIP Code. Certainly, the Code provides little guidance for an employee of a school who is in need of urgent advice on his or her powers and responsibilities.

The School Counsellor will also be required to satisfy the requirements of section $22 \mathrm{~F}$ of the Health Act since the section applies to "any individual." Thus the legal issues facing a school counsellor, in both intervention and prevention, are similar to those affecting the mental health professional. Both parties labour under both the HIP Code and the Health Act 1956.

Although counsellors and mental health professionals will have to face many similar difficulties, the demands of section 77 Education Act are an additional hurdle the school faces alone.

88 Accident Insurance ("Counsellor") Regulations 1999, S R 1999/166, rr 2,4 and 5.

89 Of counsellors surveyed, 17 per cent address suicidal behaviours unsupervised.

90 Although the New Zealand Association of Counsellors has established valuable Codes of Ethics and Supervision, only 344 school counsellors elect membership to the Association. There are 447 secondary schools in New Zealand many of which employ more than one counsellor. Courtesy James Shepherd, Executive Officer, NZAC (27 October 1999).

91 The survey demonstrated that in addition to the 28 schools that do not have counsellors, 20 schools employed counsellors with no qualification more specific than teaching or religion. 


\section{Section 77 Education Act 1989}

Section 77 requires a school principal to take all reasonable steps to tell parents of all hindrances to a student's progress, including matters that are affecting a student's relationships with teachers. Obviously, chronic suicidal behaviours will qualify as a hindrance to a student's progress. There is however a fundamental conflict between section 77, obligations of the Health Act and HIP Code and the best interests of the young person.

As has been seen, there is a complex and sometimes confusing matrix of statutory duties and discretions for breaching an individual's confidence. Yet section 77 of the Education Act ignores these difficulties and leaves no room for a principal to decline to inform parents, neither when the young person is sufficiently competent to exclude parents from their treatment, nor when acute suicidal symptoms are caused by family abuse. Section 77 also fails to take into account the circumstances involved in coming upon the information, which often involve serious issues of confidence and privacy. Because section 77 ignores both the counsellor's confidential relationship with the pupil and the effects of disclosure on the young person, it is unclear how it relates to other law identified here.

One solution, implicitly endorsed by the Guideline for Schools, ${ }^{92}$ is to focus on the different identities involved in the two schemes. The Education Act compels principals to disclose while the HIP Code and Health Act are likely to be restricted to the school counsellor alone. Decisions to inform the principal that a pupil is a high risk of suicide might be made in accordance with the Health Act and HIP Code, taking into account the principal's duty to inform parents.

Although that reading would be most sensible, it is not made clear by either the law or the Guideline. It might also be counterintuitive given the counsellor's employment relationship with the Board of Trustees. ${ }^{93}$ A serious concern is that the nature of that relationship might bring illegitimate pressure on the counsellor's decisions to inform a principal.

The New Zealand Association of Counsellors requires that: ${ }^{94}$

92 The guideline declares that a staff member should "consult with the principal who will then inform the appropriate staff": Guidelines For Schools, above n 16, 31.

93 Robert Ludbrook The School Counsellor and the Law (New Zealand Association of Counsellors, Auckland, 1992) 6.

94 New Zealand Association of Counsellors Handbook: Code of Ethics (Hamilton, 1998) 18. 
Counsellors should adhere to and uphold the ethics of the profession and should avoid compromising them in the face of institutional requirements.

Regrettably the relationship between section 77 and counsellors' duties of confidentiality fails to address that issue. Worse, the ambiguity of the law is likely to contribute to an environment where the respective roles of the counsellor vis-à-vis the school are confused. This situation falls well short of guaranteeing protection of a suicidal young person's best interests.

\section{Disclosures of information not involving the counsellor}

In 1998 the schools surveyed made 444 disclosures to parents that their child was in danger of suicidal behaviour, substantially less than the 638 referrals made to mental health agencies. More interesting again was the fact that schools recorded 759 referrals from staff that a pupil was in danger of suicide. In close to half the cases then, parents were not contacted when a staff member reported some risk of suicidal behaviour. Because there is no legal requirement that assessments and referrals involve a specifically qualified counsellor, it could be that these decisions are made by a principal or staff member.

Since general staff would not qualify as health agencies for the purposes of the HIP Code, questions of disclosure by general staff would be governed by the Privacy Act alone. It may be that suicidal tendencies identified from a young person's school work will amount to use of information for a purpose other than that for which it was obtained. ${ }^{95}$ The school may also believe that the student would not consent to any disclosure, prima facie breaching Privacy Principle 11. Although both principles 10 and 11 include the serious and imminent harm exception, they are ill-equipped to deal with the specific needs of the suicidal adolescent who is the subject of abuse or who may require culturally relevant treatment. In fact, having decided that a young person is suicidal, a principal is obliged to inform parents regardless. ${ }^{96}$ It would certainly be anomalous if a system required set responses from an appropriately qualified counsellor but allowed them to be circumvented by general staff. Unfortunately that absurdity remains under the current regime.

95 Privacy Act 1993, s 6 Privacy Principle 10.

96 Education Act 1989, s 77. 


\section{Disclosures to Schools}

\section{Disclosures to schools in emergencies}

If an outside party, either a health professional or family, is aware that a student is in serious and imminent danger of self harm as a result of an acute suicidal episode, there will generally be no need for a school to be informed. In those circumstances, schools are probably inappropriate institutions to disclose information to under rule 11(2)(d) of the HIP Code or at common law.

In all likelihood, a pupil will only return to school once the intensity of suicidal behaviours subside. At that point, a school gains an interest in aspects of the pupil's wellbeing that enable it to fulfil its various legal obligations to a broader range of parties.

\section{Disclosures to schools in the course of treatment}

Because schools exercise significant levels of control and influence over young people's well-being, they have the potential to play an active role in suicide treatment and management.

Despite that, 38 per cent of school principals felt they were not involved in a pupil's suicide management plan. This trend was particularly pronounced in the smaller schools, where a number of surveyed principals also commented that the issue was a particular concern.

One way for mental health agencies to justify disclosures to schools may be to adopt the exception in rule 11(2)(i) HIP Code which permits disclosure of health information if it is "necessary to avoid prejudice to the maintenance of the law by a public sector agency or for the conduct of proceedings". ${ }^{97}$ This discretion normally entails disclosures to the Police in order to maintain law and order or to the Department of Child Youth and Family Services in conjunction with the Children Young Persons and Their Families Act. It might be argued that there is a discretion to disclose a pupil's suicidal tendencies to a school in order that it may fulfil its obligation to provide a safe environment as required by the National Administrative Guidelines. ${ }^{98}$ That conclusion could have the benefit of allowing closer communication

97 Health Information Privacy Code 1994, rule 11(2)(i).

98 Section 61(2) Education Act 1989 states that all charters are deemed to contain the goals and objectives in National Education Guidelines ("NEGs"). National Administrative Guidelines ("NAGs") make up a third of the NEGs. Guideline 5 of the NAGs requires a school to provide a safe physical and emotional environment for students. 
between mental health professional and school counsellor. A number of practical benefits are apparent.

One school counsellor reported that girls who are considered a particular suicide risk were able to be more closely monitored. "If they do not turn up to class at 9:15 am there is an immediate call home." The school counsellor may also play a role in assisting with administration of medication, facilitation of peer support and ongoing counselling. These may be particularly important in rural settings where distance from mental health service providers makes ongoing care difficult. But again, that reading of the HIP Code is not one that would be obvious to mental health professionals and even then only delivers a discretion.

\section{$V$ SUMMATION AND RECOMMENDATION}

\section{A The Need For A Specific Regime}

The Mason Inquiry wrote that: ${ }^{99}$

The difficulty with a set of guidelines or rules is that it may be inconsistent with a particular type of service delivery or service provided. The Act and Code set out objectives and principles on handling information to avoid interference with privacy. However there are several different ways or means to achieve those objectives.

The Mason Inquiry recognised that the Health Act and HIP Code leave much to be desired in some contexts. Their ability to appropriately deal with suicidal young people is surely a case in point. Generally, the application of the HIP Code has been characterised by misunderstanding and confusion, particularly of the principle of patient confidentiality. ${ }^{100}$ Its relationship with the Health Act is far from clear, making deciphering of obligations a difficult task even for those with some legal experience. Furthermore, the compliance with the Code requires investigation of the Health and Disabilities Services Act 1993, repealed regulations of ARCIA Act 1992 and the Privacy Act 1993. It is little wonder that the Mason Inquiry concluded that: ${ }^{101}$

99 Mason Report, above n 9, 54.

100 Kristy McDonald "Ignorance no defence in health privacy law" in Health Information and Privacy in New Zealand (Office of the Privacy Commissioner, Wellington, 1995) 85.

101 Mason Report, above n 9, 52. 
[Privacy] problems have arisen largely from a lack of knowledge and understanding and misrepresentation of the Act and Code.

The fact that other obligations and remedies exist outside the Health Act and HIP Code also complicates both treatment and intervention. In particular, it is difficult to predict the effect of equitable and contractual obligations on some relationships involved in suicide management. More difficult is deciphering whether a mental health professional, a school or a counsellor owe a duty to warn others at common law. Trying to apply these already complicated legal regimes to the particular demands of youth suicide management is a Herculean task.

The law also does little to take into account different roles that underpin delivery of suicide management regimes, in particular the role of the school counsellor. In addition, the potential that the family has played a direct role in precipitating acute suicidal behaviours in the young person is ignored. Not only does the law fail to appropriately deal with suicidal adolescents, it exposes parties involved in management to potential liabilities that cannot readily be determined. If ever there were a case for a separate regime to "achieve the objectives" of privacy and confidentiality law as envisaged by the Mason Inquiry, this is it.

\section{B Protecting the Young Person And The Confidence: A Balance}

A major concern involved in disclosures of information, whether by family, counsellor or mental health professional, is that a breach of trust might undermine the particular relationship as a future vehicle for the child's protection. Indirectly, a breach of trust may also influence the professional's reputation among other suicidal young people.

In response to that danger, the literature strongly endorses the notion that service providers make known to patients how privacy and confidentiality issues are handled before information is obtained. ${ }^{102}$ The Guideline to Schools states that: ${ }^{103}$

Conflicts about confidentiality need to be resolved early in the assessment and the limits of confidentiality established in each situation.

To that end Edwards and Paff argue that professionals should never promise that they will keep a secret in all circumstances. ${ }^{104}$ Despite these recommendations there is currently no

102 Mason Report, above n 9, 54.

103 Guidelines for Schools, above n 16, 35. 
legal obligation that requires a professional to inform a young person about the extent of confidentiality.

A duty to inform the adolescent would lessen the chance that the young person would blame the counsellor for breaches of confidence. The young person's trust could be preserved by informing them at the commencement of treatment that the counsellor is required by law to be independently supervised, and that in extreme circumstances the law requires the supervisor to inform parents and/or mental health agencies of risks of physical harm. The health professional or counsellor could divert blame for the disclosure to "the law", thereby preserving their relationship with the individual and their reputation within the community.

Explaining to young people that parents, mental health professionals or school counsellors may be informed if they pose a serious and imminent risk of serious harm may deter some young people from seeking assistance. However, it would be likely to deter far fewer adolescents than the current regime that "betrays" them.

A duty to inform young people must also make clear that the young person's confidence is of utmost importance. It should be clear that anything short of serious and imminent danger, linked to high risk assessment by professional and independent supervisor, cannot be disclosed provided the young person is competent. Competence to exclude parents from treatment must include suicide prevention information.

\section{A Duty to Inform Parents: Health Professionals and Schools}

A duty to inform parents should operate in much the same way for both health professional and counsellor. Previous sections have shown that obligations on both parties to inform parents of their child's suicidal behaviours are complicated and uncertain. Potentially, a common law duty to warn may conflict with discretions of the HIP Code. Add to that complexity the incoherent provisions of the Health Act, potential obligations from other legal sources and the delicate psychological causes of adolescent suicide. In sum, there is no certainty that decisions to disclose information are principled or consistent.

A regime that better secures the best interests of the young person is in order. The approach taken by section $22 \mathrm{~F}$ of the Health Act in combination with rule 11(4) of the HIP Code has potential. By obliging both school counsellors and mental health agencies to

104 S J Edwards and J J Pfaff The 4R's: Managing Youth Suicidal Behaviour: A Guide for General Practitioners and Community Health Personnel (Department of Health and Family Services, Perth, 1997) in Guidelines to Schools, above n 16, 36 . 
consider the best interests of the young person, the rule gives the young person's interests primacy. Although this article would support a similar duty, as they stand section $22 \mathrm{~F}$ of the Health Act and rule 11(4) are inadequate and require overhaul in a number of areas.

Section 22F and rule 11(4) do not provide counsellors or health professionals with clear, concise or complete standards on which to decide whether to disclose. The fact that there are currently two distinct pieces of legislation dealing with the same issues is plainly undesirable. ${ }^{105}$ A separate regime could stipulate specific obligations for school counsellors instead of requiring them to decipher whether they come within the scope of rule 4(2) of the HIP Code.

In most instances a prima facie duty on schools and health professionals to inform parents will enable the necessary support network for suicidal young people. But like rule 11(4), the duty must be rebuttable. A counsellor should not disclose information to parents when it is not in the young person's best interests.

Unlike rule 11(4), a rule should also stipulate a range of criteria relevant in deciding what is in the best interests of the young person. Where the young person is competent and not assessed as high risk, their wish to exclude parents should be key. Other factors that might affect the best interests of the child would include the possibility of sexual or physical abuse. Further criteria could be defined by the Minister of Health through delegated legislation as understanding of suicidal behaviours increases and the best interests of the suicidal adolescent become clearer. These criteria could also be cross referenced to care and protection provisions in section 14 of the Children Young Persons and Their Families Act 1989 which currently set the legal standards for disposing of the families right to involvement, and to sections 15 and 16 which create immunities for reports to Police and the Department of Child Youth and Family Services made in good faith.

It is also important to note that section $22 \mathrm{~F}$ and rule $11(4)$ leave 16 to 19 year olds to suffer the uncertainties of the disclosure rules applicable to adults. This is in spite of the fact that rates of suicide in this country begin to escalate dramatically at 16 years. A practical response would be to extend the duty to all school pupils, adopting too the proposed best interests exception. This need not compromise privacy issues since a decision to disclose could only be made where the pupil demonstrated high suicide risk, as assessed by professional and supervisor.

105 Peart, above n 40, 99. 
For the education institution specifically, regulation of the role of the school counsellor could ensure that decisions to refer suicidal young people are carried out by those with specific training, experience and support. It could also ensure that the suggestions here cannot be so easily circumvented by assessments made by general staff. That process will require clarifying the legal relationship between school counsellors and other members of the school: an area where current law is plainly deficient.

\section{A Health Agency's Duty to Inform the School Counsellor}

Currently, a health professional may enjoy a discretion to disclose certain patient information to a school under rule 11(2)(i) of the HIP Code although that interpretation is less than obvious on the terms of the section. It is certainly strange that a school counsellor does not rank alongside medical officers of penal institutions, probation officers, social workers, care and protection co-ordinators and police officers, as parties which have a legitimate interest in receiving such information under section 22C Health Act 1956.

Even accepting the interpretation of rule 11(2)(i) of the HIP Code, it is questionable whether a technical discretion goes far enough in protecting the suicidal young person or his or her peers. A positive duty on mental health professionals to disclose limited information to a school counsellor would go some distance in allowing schools to fulfil their management obligations. The duty could avoid unwarranted intrusions into the young person's privacy by only disclosing information to the school counsellor and only informing them that the young person's wellbeing should be closely monitored.

Most of those requirements could be given legal effect through the Privacy Commissioner's issue of a new code pursuant to section 46 Privacy Act. Yet that process would perpetuate the ambiguities between the Health Act 1956, the HIP Code, common law and other sources of confidentiality law. The more appropriate solution is separate legislation, which could preclude those ambiguities and address numerous other failings of the law in dealing with youth suicide management in New Zealand.

\section{CONCLUSION}

In 1998, 78 people between the ages of 10 and 19 committed suicide in New Zealand. This research has addressed an important aspect of law in dealing with that crisis. It has found that the difficulties inherent in suicide management have been exacerbated by a privacy and confidentiality scheme that does not cater to the needs of suicidal young people. It is far from clear when and how schools, health professionals and parents are justified in involving each other. What is clear is that the system can ill afford such confusion. For these reasons the law 
falls well short of meeting the "challenge for government and community", ${ }^{106}$ sounded by the issue of the New Zealand Youth Suicide Prevention Strategy. The legal changes suggested here will be one important step in achieving those objectives. It is, after all, time that we as a community began to take the crisis seriously.

106 Prevention Strategy, above n 6, 6. 